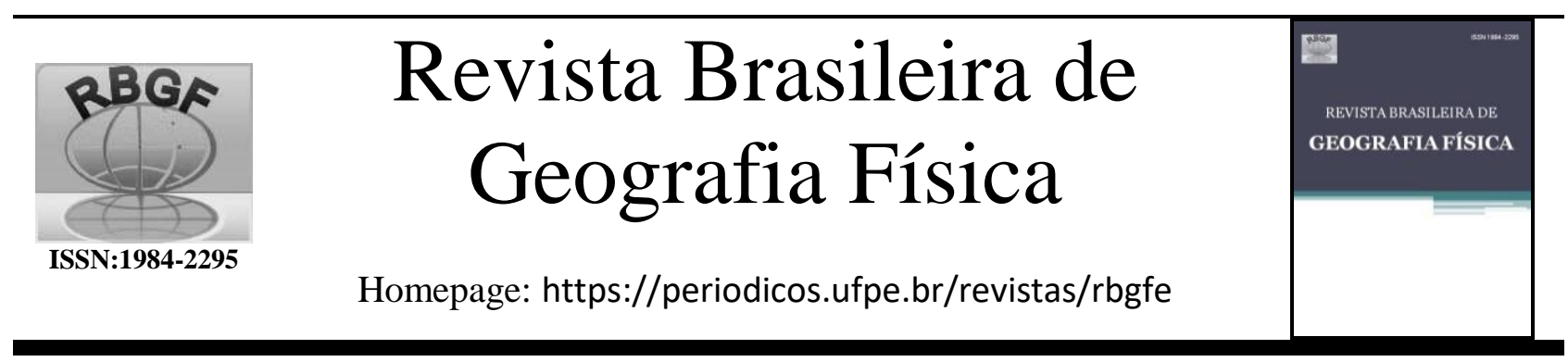

\title{
Avaliação de metodologias de transferência de vazões de referência em bacias hidrográficas: sua aplicação na bacia do rio Japaratuba - Sergipe - Brasil
}

\author{
Marcus Aurélio Soares Cruz ${ }^{1}$, José Carlos de Anunciação Cardoso Junior ${ }^{2}$, Amanda de Azevedo \\ Gonçalves ${ }^{3}$, Júlio Roberto Araújo de Amorim ${ }^{4}$ e Ricardo de Aragão 5 \\ ${ }^{1}$ Dr. em Recursos Hídricos e Saneamento Ambiental, Pesquisador, Embrapa Tabuleiros Costeiros, Av. Beira Mar, no 3250, Jardins, CEP 49025-040, \\ Aracaju, Sergipe. (79) 4009-1300. marcus.cruz@embrapa.br (autor correspondente). ${ }^{2}$ Me. em Recursos Hídricos, Universidade Federal de Sergipe, \\ Av. Marechal Rondon, s/n, Rosa Elze, São Cristóvão, Sergipe. jcacjr2@yahoo.com.br. ${ }^{3}$ Doutoranda em Eng. de Processos, Universidade Tiradentes, \\ Av. Murilo Dantas, n³00, Farolândia, CEP 49032-971, Aracaju, Sergipe. amanda_engambiental@ hotmail.com. ${ }^{4}$ Me. em Eng. Agrícola, Pesquisador, \\ Embrapa Tabuleiros Costeiros, Av. Beira Mar, $n^{\circ}$ 3250, Jardins, CEP 49025-040, Aracaju, Sergipe. julio.amorim @embrapa.br. ${ }^{5}$ Dr. em Engenharia. \\ Professor associado, Universidade Federal de Campina Grande, Av. Aprígio Veloso, no882, Universitário, CEP 58429-900, Campina Grande, Paraíba. \\ ricardoaragao2005@gmail.com.
}

Artigo recebido em 06/08/2020 e aceito em 19/014/2021

\section{R E S U M O}

Para avaliar a disponibilidade de água e definir as áreas de inundação nas bacias hidrográficas, é necessário considerar a vazão mínima, média e máxima, denominadas de vazões de referência, e isto requer dados observados de vazão, que são bem escassos em bacias brasileiras, principalmente as pequenas e médias bacias. Para superar esta falta, utiliza-se dados de bacias contribuintes com comportamento hidrológico similar, que são transferidos por meio de operações matemáticas, utilizando variáveis físicas e climáticas. Tais procedimentos, geralmente, são mal avaliados quanto à sua precisão. Assim, objetivou-se avaliar a acurácia da estimação de cinco vazões de referência em quatro estações de medição dos dois principais afluentes do rio Japaratuba (Sergipe, Brasil), os rios Japaratuba-Mirim e Siriri. Os resultados mostraram diferentes comportamentos para as duas sub-bacia, quer seja pelas variáveis influentes, quer seja pelos efeitos antrópicos como a mudança no uso do solo que precisam ser melhor avaliados. Para a bacia do rio Japaratuba-Mirim a transferência de vazões mínimas e médias deve ser realizada considerando-se o produto área x precipitação média anual e para as vazões máximas deve-se considerar o comprimento do rio até a seção. Para a bacia do Siriri, os melhores resultados de transferência de vazões médias e máximas foram obtidos com o produto "área x precipitação média anual" e a variável "precipitação média anual" gerou um erro menor para as vazões mínimas.

Palavras-chave: Gestão dos recursos hídricos; Hidrologia estatística; Sistemas de informações geográficas.

\section{Assessing the reference flow transfer methodologies in watersheds: their application at Japaratuba River Basin - Sergipe State - Brazil}

\section{A B S T R A C T}

In order to evaluate the water availability and define the flood areas in the river basins, it is necessary to consider minimum, medium and maximum discharge, called reference flows requiring records on flow data, quite scarce in Brazilian river basin, mainly those of small and medium scale. To overcome this gap, data from nearby basins with similar hydrological behavior are used, based on mathematical operations involving physical and climatic variables of the contributing basins. However, these procedures are poorly evaluated for their accuracy. Thus, this study aimed to evaluate the accuracy of the estimation of five reference flows through the transfer of information, using physical and climatic variables in four gage stations of the main tributaries of the Japaratuba river basin (Japaratuba-Mirim and Siriri river) - Sergipe State, Brazil. The results showed different behaviors for the two sub-basins as for either by influential variables or by anthropic effects such as land use and land cover changes that need to be better evaluated. The flow transfer to the subbasin of the Japaratuba-Mirim river should be performed considering the product "Area x Mean annual rainfall" for minimum and medium flows. For maximum flows the "Length" of the basin should be considered. For the Siriri river basin, the "Mean annual rainfall" variable generated a smaller error in the minimum flows and the product "Area x Mean annual rainfall" led to better results for medium and maximum flows.

Keywords: Water resource management; statistical hydrology; geographic information systems. 


\section{Introdução}

A água está no centro do desenvolvimento sustentável, por ser essencial para a existência da humanidade no planeta. Os recursos hídricos e os serviços associados a eles, sustentam os esforços de sustentabilidade ambiental, crescimento econômico e erradicação da pobreza. Atualmente, a população mundial sofre com mais de $40 \%$ de escassez da água, número que deverá subir devido às mudanças climáticas e à gestão inadequada dos recursos naturais (ONU, 2015; ONU, 2020).

Mudanças climáticas, crescimento populacional e aumento da demanda de água para as atividades agrícolas e industriais aumentam o desafio para a implementação da gestão integrada dos recursos hídricos (Prieto et al., 2015; Al-Jawad et al., 2019), isso porque esses fatores contribuem para o desequilíbrio nos corpos d'água, conflitos pelo uso da água e vazão de rios insuficientes para sustentar a biota aquática (Silva, Bassi e Rocha, 2016; Zhao et al., 2020).

A Lei 9433/97 (BRASIL, 1997), que estabelece a Política Nacional de Recursos Hídricos (PNRH), visa organizar o planejamento e a gestão dos recursos hídricos em âmbito nacional. Assim, a outorga de direito de uso da água, um dos instrumentos do PNRH, busca tratar das questões hídricas e dos diferentes usos da água. Dessa forma, estudos de disponibilidade hídrica são realizados considerando as vazões mínimas e médias de longo prazo em um curso d'água (ANA, 2013). Por outro lado, os mapas de risco de inundação são determinados pelas profundidades e velocidades de fluxo, resultantes das vazões máximas em períodos de retorno padronizados (Młyński et al., 2020; Silva e Manzione, 2020). Esta vazão máxima de uso da água de um dado curso d'água é denominada de vazão de referência (ANA, 2013; Santos, 2019; Tormam et al., 2020).

Segundo Silva e Bassi (2016) e Gomes e Fernandes (2017), existem diferentes padrões para adoção de vazões de referência no Brasil, e a variabilidade desses padrões está relacionada às características individuais de cada bacia hidrográfica, principalmente quando se trata de vazões mínimas. Por isso, ocorre uma diferença de valores de referência considerados para outorga do uso da água (Bezerra et al., 2013; Silva, Silva e Moreira, 2015).

As vazões mínimas como $\mathrm{Q}_{7,10}$ e as vazões de permanência $\mathrm{Q}_{90 \%}$ e $\mathrm{Q}_{95 \%}$ são, geralmente, utilizadas como vazões de referência. O Brasil e seus estados federais definem seus próprios percentuais do fluxo de referência como o fluxo máximo para usos consultivos (Gomes e Fernandes, 2017; Morais et al., 2020). Por exemplo, no Estado de Sergipe utiliza-se uma vazão de referência de $90 \%\left(\mathrm{Q}_{90}\right)$ ao longo de um ano (SERGIPE, 2015).

A determinação do fluxo de referência exige análises estatísticas sobre séries históricas de longo prazo de fluxos em um trecho de interesse em um determinado rio (Tucci, 2013). Porém, pela extensão continental do Brasil, a medição de cursos d'água muitas vezes não abrange todas as regiões de interesse (Melati e Marcuzzo, 2016). Por isso, faz-se necessário estudos que ampliem as informações fluviométricas existentes e, paralelamente ao procedimento de outorga, propaguem ações técnicas que mitiguem ou eliminem o efeito da falta de dados. Dentre as técnicas disponíveis para tal, a regionalização encontra muito espaço por produzir bons resultados (Lelis et al., 2019; Colegario et al., 2020; Silva, 2020).

$\mathrm{Na}$ hidrologia, a regionalização é uma técnica que permite a transferência de dados entre pontos onde existe uma estação fluviométrica instalada para pontos sem informação (Lelis et al., 2019; Zhao et al., 2019; Yang et al., 2020). Apesar das peculiaridades intrínsecas desse tipo de avaliação, a maioria das pesquisas recomenda aplicação de variáveis morfométricas, como área ou declividade média, associadas a uma variável climática, como a precipitação anual, conforme citados por Nruthya e Srinivas (2015), para permitir esta regionalização.

As características supracitadas são encontradas na bacia do rio Japaratuba, Estado de Sergipe, onde estão instaladas cinco estações hidrométricas - uma no rio principal (rio Japaratuba), duas no rio Siriri (afluente principal do lado direito) e duas no rio Japaratuba-Mirim (tributário principal no lado esquerdo). Essa bacia tem grande importância para o estado, pois nela desenvolvem-se atividades como mineração (gás natural, petróleo, potássio), agricultura (cana-deaçúcar, milho) e pecuária. Essas atividades demandam grande volume de água e geram grandes volumes de efluentes (Maynard; Gomes; Cruz, 2017; Acieri et al., 2019), portanto, dependem de bons programas de gestão da água e do conhecimento dos limites de referência de cada curso d'água da bacia hidrográfica. 
Nesse sentido, o objetivo do presente estudo foi avaliar a eficácia da estimativa de vazões mínimas, médias e máximas de acordo com a transferência de informações entre estações hidrográficas, auxiliando o processo de gestão dos recursos hídricos no Estado de Sergipe. Essa metodologia já foi aplicada no gerenciamento das águas no Estado, mas considerando apenas as variáveis morfométricas e climáticas da bacia hidrográfica do rio Japaratuba.

\section{Material e métodos}

\section{Caracterização da área de estudo}

A bacia do Rio Japaratuba cobre 1.665 $\mathrm{km}^{2}$, e corresponde a 7,65\% da área total do Estado de Sergipe. A bacia hidrográfica está localizada entre os paralelos $10^{\circ} 14^{\prime}$ e $10^{\circ} 48^{\prime}$ de latitude Sul e os meridianos $37^{\circ} 18^{\prime}$ e $36^{\circ} 48^{\prime}$ de longitude Oeste de Greenwich, Noroeste de Sergipe. Esta bacia compreende dezenove municípios, sendo três deles totalmente inseridos na bacia (Carmópolis, Cumbe e General Maynard) e os outros dezesseis parcialmente inseridos (Aquidabã, Barra dos Coqueiros, Capela, Divina Pastora, Feira Nova, Graccho Cardoso, Japaratuba, Maruim, Malhada dos Bois, Muribeca, Nossa Senhora das Dores, Pirambu, Rosário do Catete, Santo Amaro das Brotas e Siriri) (Figura 1-A) (Maynard; Gomes; Cruz, 2017).

O Rio Japaratuba com aproximadamente $135 \mathrm{~km}$ de extensão, é o principal rio da bacia e suas nascentes situam-se na Serra da Boa Vista, entre Feira Nova e o município de Graccho Cardoso. Deságua entre os municípios de Pirambu e Barra dos Coqueiros; seus principais afluentes são os rios Japaratuba -Mirim, Siriri, Lagatixo, Canelo, Cajueiro, Calomba e Riacho do Prata (Aragão et al., 2013; Acieri et al., 2019).

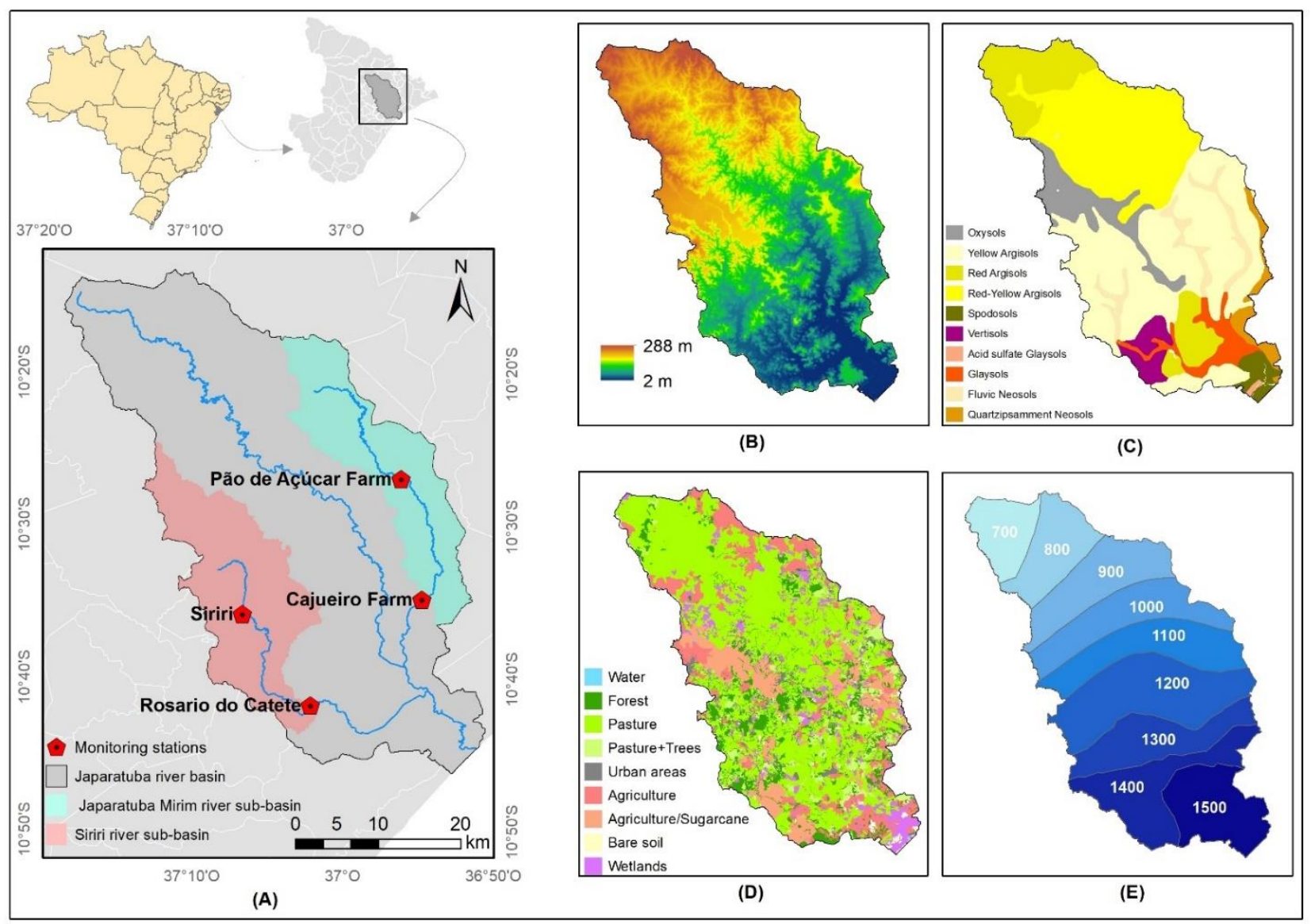

Figura 1. Localização da bacia do Rio Japaratuba e das principais sub-bacias utilizadas no estudo atual e apresentando estações de monitoramento de vazão (A); Mapas de altimetria (B); Classes de solo (Aragão et al., 2013) (C); uso do solo (Aragão et al., 2013) (D); e isoietas de precipitação média anual (Aragão et al., 2013) (E). 
A bacia hidrográfica do Rio Japaratuba atravessa o Estado de Sergipe (Oeste a Leste) e está sujeita as seguintes regiões climáticas distintas: região subúmida, que representa $57 \%$ da bacia, temperatura entre $19^{\circ} \mathrm{C}$ e $32^{\circ} \mathrm{C}$, evapotranspiração média anual de $1200 \mathrm{~mm}$ e média anual pluviometria de $1500 \mathrm{~mm}$; Região do Agreste, que representa cerca de $30 \%$ da bacia; temperatura entre $18^{\circ} \mathrm{C}$ e $33^{\circ} \mathrm{C}$, evapotranspiração média anual: $1400 \mathrm{~mm}$; pluviometria média anual: $900 \mathrm{~mm}$; e Região Semiárida: representa $13 \%$ da bacia; temperatura entre $16^{\circ} \mathrm{C}$ e $36^{\circ} \mathrm{C}$, evapotranspiração média anual: $1500 \mathrm{~mm}$; pluviometria média anual: 700 mm. (Figura 1-E). Segundo a classificação de Köppen, o clima tropical predomina na região, com uma estação seca e outra chuvosa. O período de chuvas vai de abril a agosto, e os maiores volumes de chuva são registrados nos meses de maio, junho e julho (SERGIPE, 2015; Cruz et al., 2019).

Segundo Sergipe (2015), é possível observar (Figura 1-C) a prevalência de Argissolos na bacia do Rio Japaratuba $(77 \%$ da área), seguidos pelos Latossolos (7\%) e Neossóis (7\%). Existem também Gleissolos (4\%), Verissolos (3\%) e Espodossolos (2\%), mas em menor escala.

A bacia do Rio Japaratuba concentra 6,3\% da população do estado, onde sua população urbana é de 127.350 habitantes e sua população rural de 74.069 habitantes (SERGIPE, 2015). O uso e a cobertura do solo na bacia são bastante diversificados (Figura 1-D), predominando na região atividades pecuárias como pastagem $(56 \%$ da área total) e culturas agrícolas (23\%). As florestas respondem por $11 \%$ da área total, as terras úmidas correspondem a $8 \%$ do total, assim como os solos expostos e as áreas urbanas correspondem a 2\% dela (Aragão et al., 2013; Maynard et al, 2017).

A cultura da cana-de-açúcar corresponde a 45\% das atividades agrícolas (SERGIPE, 2015). A água disponível tem sido utilizada predominantemente para suprir as necessidades humanas e animais, atividades industriais e para fins de irrigação.

Essa bacia tem importância estratégica para Estado de Sergipe devido à existência e exploração de petróleo, gás e potássio em suas terras; além disso, vale destacar a cultura da canade-açúcar para a produção de açúcar e etanol. Essas atividades têm causado grande impacto nos recursos de água e solo da bacia ao longo dos últimos dois séculos, de modo que há poucos remanescentes de mata ciliar e mata nativa. Assim, políticas de gestão da água que permitam o uso sustentável desses recursos são necessárias, embora exijam informações sobre $o$ abastecimento de água no ponto de demanda, que podem ser coletadas por meio da determinação da vazão de referência (Lopes et al., 2017).

\section{Procedimento metodológico}

O presente estudo foi desenvolvido de acordo com as seguintes etapas:

Levantamento de dados sobre séries temporais de vazão: as séries temporais de vazão foram obtidas a partir do banco de dados de fluviometria, mantido pela Agência Nacional de Águas (ANA, 2020), através do portal HidroWeb. As estações fluviométricas localizadas na bacia do rio Japaratuba cujos dados foram aqui utilizados são listadas na Tabela 1.

Análise exploratória aplicada às séries históricas coletadas: as séries temporais de vazão foram submetidas à análise exploratória para verificação da consistência dos dados, bem como à avaliação de falhas. Os parâmetros estatísticos de tendência central e dispersão foram definidos através de planilha eletrônica e de gráficos das séries para detecção de falhas e outliers.

Cálculo das vazões de referência: as seguintes vazões de referência foram calculadas com base na série histórica de cada estação fluviométrica: $\mathrm{Q}_{\mathrm{med}}$ - vazão média diária de longo prazo; $\mathrm{Q}_{7,10}$ - vazão mínima com duração de 7 dias e período de retorno de 10 anos; $Q_{90}$ - vazão com 90\% de permanência na série; $\mathrm{Q}_{\mathrm{TR}=10 \mathrm{anos}}$ - vazão máxima com período de retorno de 10 anos; $\mathrm{Q}_{\mathrm{TR}=50 \text { anos }}$ - vazão máximo com período de retorno de 50 anos (Bazzo et al., 2017). Essas vazões de referência foram calculadas por serem utilizadas frequentemente nos planos estaduais de recursos hídricos no Brasil, envolvendo vazões ecológicas, limites de outorga, disponibilidade hídrica, regularização de vazões e delimitação de faixas de domínios para cheias, conforme indica Lopes et al. (2017) e Lelis et al. (2019)

Metodologia para definição da vazão de referência: $\mathrm{Q}_{\text {med }}$ foi definida através da média das vazões diárias da série histórica disponível. Em relação ao presente estudo, foram necessários, pelo menos, oito meses do ano como critério mínimo para levar em consideração o ano abordado.

A vazão $Q_{7,10}$ foi obtida por meio de ajustes feitos em funções de probabilidade como as de Gumbel ou Weibull (Tucci, 2013; Melati e 
Marcuzzo, 2016; Maciel et al., 2019), sendo selecionada aquela de melhor aderência aos dados observados. Primeiro, as medias móveis de 7 dias foram obtidas; a seguir, foram calculadas as vazões mínimass anuais das médias móveis. As distribuições de probabilidade Weibull e Gumbel foram escolhidas por apresentarem melhores ajustes às estações selecionadas, segundo estudos já realizados previamente na bacia (Acieri et al., 2019).

A vazão $Q_{90}$ foi obtida através das curvas de permanência das estações selecionadas segundo a técnica simplificada de ordenamento de vazões (Tucci, 2013; Schneider et al., 2019). A seleção dos períodos, no caso da presença de falhas, considerou anos em que os meses de setembro a março tivessem registros, pois concentram as vazões mínimas da série. As vazões $\mathrm{Q}_{\mathrm{TR}=10 \text { anos }} \mathrm{e} \mathrm{Q}_{\mathrm{TR}=50 \text { anos }}$ também foram determinadas por meio de ajustes feitos nas funções de probabilidade Gumbel ou Weibull.

Neste caso, os anos com falhas foram avaliados, sendo mantidos aqueles que apresentavam registros completos nos meses de abril a agosto. Para a realização dos ajustes das distribuições de probabilidade e avaliação por meio do teste de aderência de KolmogorovSmirnov, foi utilizado o software $\mathrm{R}$ versão 3.0.3. (R Core Team, 2018).

Obtenção das variáveis físicas e climática: a avaliação da precisão na transferência das vazões de referência considerou como variáveis físicas: área da bacia contribuinte ao posto, a declividade média da bacia e o comprimento do rio para aquela seção da bacia e como variável climática: a precipitação média anual. Foi também avaliado o produto entre a área e a precipitação média anual.

Os valores das variáveis foram obtidos a partir da aplicação de técnicas de geoprocessamento tendo como banco de dados a Base de Dados do Projeto Japaratuba (Cruz et al., 2019). As precipitações médias anuais de cada bacia contribuinte foram obtidas a partir da ponderação pela área considerando as isoietas disponíveis (Figura 1-(E)).

A estimativa das vazões de referência em um posto $j$ foi realizada por meio da razão simples entre a vazão de referência observada em um posto $i$ e cada variável física, climática ou produto entre área da bacia e precipitação, da área contribuinte a este posto $i$. Posteriormente, esta razão obtida foi utilizada para multiplicar a variável física, climática ou produto entre área da bacia e precipitação da área contribuinte ao posto $j$, situado à montante ou à jusante de $i$ no mesmo curso d'água, obtendo assim a vazão de referência estimada no posto $j$. Assim, a avaliação foi realizada partindo do posto de montante para o posto de jusante e também no sentido inverso, ou seja, partindo do posto de maior área para o de menor, considerando que ambos estejam no mesmo curso d'água. As vazões foram transferidas entre as estações localizadas ao longo do rio Siriri (Siriri e Rosário do Catete) e entre as estações localizadas ao longo do rio JaparatubaMirim (Fazenda Pão de Açúcar e Fazenda Cajueiro). Este critério decorre do conhecimento prévio das diferenças em termos de relevo, tipos de solos, cobertura vegetal e precipitações entre as duas bacias, o que dificulta a definição de regiões homogêneas. A precisão destas estimativas foi avaliada por meio do erro médio percentual (ERR), sendo um parâmetro simples de avaliação, mas que atende a que o estudo se propõe:

$$
\operatorname{ERR}(\%)=\frac{\operatorname{Qref}_{(\text {est })}-\mathrm{Q} \mathrm{ref}_{\text {(obs) }} \times 100}{\operatorname{Qref}_{(\text {obs })}}
$$

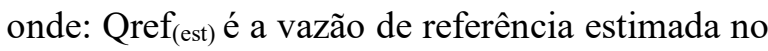
posto $i$ a partir da vazão transferida do posto $j$; Qref $_{(\text {obs) }}$ é a vazão de referência calculada no posto $i$ a partir de sua própria série histórica.

\section{Resultados e discussão}

Os postos fluviométricos selecionados apresentaram séries históricas com 35 anos de dados, na sub-bacia do Japaratuba-Mirim, e 30 anos de dados, na sub-bacia do rio Siriri. Após a exclusão de anos com muitas falhas e considerando períodos coincidentes entre os postos a serem comparados, as séries finais totalizaram 30 anos, para os postos localizados no rio Japaratuba-Mirim, e 25 anos para os do rio Siriri, com períodos iniciando em 1975 e 1973, até 2012.

A determinação das vazões de referência $\left(Q_{\text {ref }}\right)$ e vazão especifica $\left(Q_{\text {esp }}\right)$ em cada estação foi realizada e os valores obtidos estão apresentados na Tabela 2. As Figuras 2, 3 e 4 apresentam as curvas de permanência (Figura 2) e de funções de probabilidade (Figuras 3 e 4), em cada posto, para as vazões mínimas e máximas.

Observa-se que, para as vazões mínimas obtidas, a vazão $\mathrm{Q}_{7,10}$ foi sempre inferior à $\mathrm{Q}_{90}$, vazão esta que é atualmente adotada no estado de Sergipe como referencial para outorga, ressaltando, portanto, que esta escolha foi 
acertada, tendo em vista seu caráter mais conservador.

Tal resultado corrobora com outros estudos comparativos de vazões mínimas em bacias pelo mundo, tais como os citados em
Swaina e Srinivas (2015), Lopes et al. (2017) E Tormam et al. (2020), em que os resultados mostraram que a $\mathrm{Q}_{7,10}$ corresponde a valores entre $\mathrm{Q}_{98,85}$ e $\mathrm{Q}_{99,85}$ nas bacias estudadas pelos autores.

Tabela 1. Estações Fluviométricas na bacia do Rio Japaratuba utilizadas no presente estudo.

\begin{tabular}{cccccc}
\hline $\begin{array}{c}\text { Código } \\
\text { da ANA }\end{array}$ & Nome da estação & $\begin{array}{c}\text { Área de } \\
\text { contribuição } \\
\left(\mathrm{km}^{2}\right)\end{array}$ & $\begin{array}{c}\text { Coordenadas } \\
\text { geográficas } \\
\text { Longitude/Latitude }\end{array}$ & Tributário \\
\hline 50042000 & Faz. Pão de Açúcar & 99 & $36^{\circ} 56^{\prime} \mathrm{W}$ & $10^{\circ} 27^{\prime} \mathrm{S}$ & Jap. Mirim \\
50043000 & Faz. Cajueiro & 217 & $36^{\circ} 54^{\prime} \mathrm{W}$ & $10^{\circ} 34^{\prime} \mathrm{S}$ & Jap. Mirim \\
50046000 & Siriri & 150 & $37^{\circ} 06^{\prime} \mathrm{W}$ & $10^{\circ} 35^{\prime} \mathrm{S}$ & Siriri \\
50047000 & Rosário do Catete & 309 & $37^{\circ} 02^{\prime} \mathrm{W}$ & $10^{\circ} 41^{\prime} \mathrm{S}$ & Siriri \\
\hline
\end{tabular}

Tabela 2. Vazões de referência e vazões específicas calculadas para as estações fluviométricas da bacia do rio Japaratuba.

Sub-bacia do rio Japaratuba-Mirim

Sub-bacia do rio Siriri

\begin{tabular}{lccccrrrr}
$\begin{array}{l}\text { Vazão de } \\
\text { referência }\end{array}$ & \multicolumn{2}{c}{ Faz. Pão de Açúcar } & \multicolumn{2}{c}{ Faz. Cajueiro } & \multicolumn{2}{c}{ Siriri } & \multicolumn{2}{c}{ Rosário do Catete } \\
& $\begin{array}{c}\text { Qref } \\
\left(\mathrm{m}^{3} / \mathrm{s}\right)\end{array}$ & $\begin{array}{c}\text { Qesp } \\
\left(\mathrm{L} / \mathrm{s} / \mathrm{km}^{2}\right)\end{array}$ & \multicolumn{1}{c}{$\begin{array}{c}\text { Qref } \\
\left(\mathrm{m}^{3} / \mathrm{s}\right)\end{array}$} & $\begin{array}{c}\text { Qesp } \\
\left(\mathrm{L} / \mathrm{s} / \mathrm{km}^{2}\right)\end{array}$ & $\begin{array}{c}\text { Qref } \\
\left(\mathrm{m}^{3} / \mathrm{s}\right)\end{array}$ & $\begin{array}{c}\text { Qesp } \\
\left(\mathrm{L} / \mathrm{s} / \mathrm{km}^{2}\right)\end{array}$ & $\begin{array}{c}\text { Qref } \\
\left(\mathrm{m}^{3} / \mathrm{s}\right)\end{array}$ & \multicolumn{1}{c}{$\begin{array}{r}\text { Qesp } \\
\left(\mathrm{L} / \mathrm{s} / \mathrm{km}^{2}\right)\end{array}$} \\
\hline $\mathrm{Q}_{90}$ & 0.047 & 0.478 & 0.293 & 1.365 & 0.233 & 1.552 & 0.308 & 0.996 \\
$\mathrm{Q}_{7,10}$ & 0.006 & 0.063 & 0.113 & 0.522 & 0.059 & 0.396 & 0.075 & 0.243 \\
Q $_{\text {med }}$ & 0.797 & 8.013 & 1.776 & 8.131 & 0.790 & 4.817 & 2.885 & 8.895 \\
Q $_{\text {TR10anos }}$ & 34.424 & 347.712 & 52.990 & 244.194 & 22.417 & 149.448 & 81.404 & 263.443 \\
Q $_{\text {TR50anos }}$ & 47.054 & 475.290 & 69.833 & 321.810 & 33.332 & 222.211 & 120.14 & 388.804 \\
\hline
\end{tabular}

$\mathrm{Q}_{\mathrm{med}}$ - vazão média diária de longo período; $\mathrm{Q}_{7,10}$ - vazão mínima com duração de 7 dias e período de retorno de 10 anos;

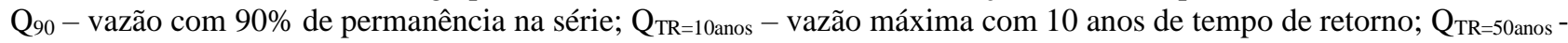
vazão máxima com 50 anos de tempo de retorno.

Visando uma análise comparativa, na Tabela 2 também estão apresentadas as vazões específicas. Observa-se que os efeitos de escala e das diferentes características de relevo, cobertura e solos das bacias contribuintes provocam uma grande variabilidade nos valores das vazões específicas, mesmo que se considere o mesmo curso d'água. Esta variabilidade foi reduzida apenas na vazão média na sub-bacia do rio Japaratuba-Mirim, onde se observa realmente uma condição mais homogênea de solos e de cobertura, com menor alteração antrópica que na bacia do rio Siriri. Nota-se também que as vazões específicas mínimas na bacia contribuinte ao posto Siriri mostraram-se superiores àquelas encontradas para a bacia do Japaratuba-Mirim. Tal fato pode estar relacionado à presença, apenas nesta região da bacia do Japaratuba, de Latossolos, que apresentam uma condição de infiltração superior, sendo classificados como Grupo Hidrológico A (SERGIPE, 2015; Acieri et al., 2019) permitindo, portanto, uma alimentação sub-superficial e subterrânea maior para os rios locais em períodos de estiagens. Há de se ressaltar que na sub-bacia da estação do Siriri, há a presença de um platô na sua porção centro-norte (Figura 1 (B)), o que resulta em escoamentos de respostas mais lentas, com predominância de armazenamentos, contribuindo para vazões mínimas maiores e redução na vazão média e nas máximas. Também há que se considerar ainda um menor volume médio anual de precipitações na porção nordeste da bacia do rio Japaratuba (área contribuinte às estações Fazenda Pão de Açúcar e Fazenda Cajueiro), conforme se observa na Figura 1 (E). Estes resultados ressaltam a dificuldade em realizar a transferência de informação considerando apenas a variável "área contribuinte", por exemplo, como parâmetro na bacia do rio Japaratuba. Este fato também foi ressaltado por Santos et al. (2019), onde os 
mesmos atribuíram as heterogeneidades na bacia como fatores influentes.

Como ilustrado na Figura 2, as curvas de permanência mostraram comportamentos similares para os casos A, B, C, com indicativo de menor capacidade de amortecimento, principalmente na sub-bacia contribuinte à estação Rosário do Catete, onde a amplitude entre as vazões máxima e mínima foi bem superior às demais, indicando maior severidade de secas e cheias neste local.

Ressalte-se que a forma da sub-bacia do rio Siriri, não tão alongada quanto a do rio Japaratuba Mirim, tende a concentrar as respostas a eventos de precipitação em tempos similares até o seu exutório, ratificando a tendência a ocorrência de cheias mais severas.

A curva de permanência relativa aos dados da estação Siriri apresenta-se com o patamar bem mais horizontal, refletindo a condição de maior amortecimento nas vazões, resultante, principalmente, de sua conformação de relevo, já mencionada anteriormente, fato também observado por Javeed et al. (2015) e Gomes et al. (2017).

Na Figura 3 estão apresentados os gráficos obtidos via software $\mathrm{R}$, ilustrando os ajustes das funções de probabilidade aos dados medidos. Observa-se que, excetuando-se o posto Fazenda Pão de Açúcar, onde a melhor representação deuse pela distribuição de Weibull, ambas as distribuições estatísticas mostraram bom desempenho visando fornecer os valores de vazões $Q_{7,10}$. No entanto, segundo o teste de Kolmogorov-Smirnov, selecionou-se Gumbel para as demais. Comportamento inverso foi percebido quanto aos ajustes de funções de probabilidades para vazões máximas, onde para a estação Fazenda Pão de Açúcar, selecionou-se a distribuição de Gumbel e, nos demais postos, a distribuição de Weibull mostrou-se mais adequada aos dados, levando-se em conta a necessidade de estimar as vazões com períodos de retorno de 10 e 50 anos.

Obtidas as vazões de referência, foram então determinadas as variáveis físicas e climáticas a serem utilizadas na transferência da informação entre os postos. Assim, na Tabela 3 estão listados os valores obtidos por meio da aplicação de técnicas de geoprocessamento na delimitação de bacias contribuintes, declividade média de cada bacia e comprimento do rio até a seção, além da precipitação média anual sobre cada bacia contribuinte. Observa-se que os valores obtidos de áreas contribuintes aos postos diferem dos valores originais disponibilizados no portal HidroWeb (Tabela 1), principalmente para a subbacia do rio Japaratuba-Mirim (estações Fazenda Pão de açúcar e Fazenda Cajueiro).

Considera-se que, diferente dos valores apresentados na Tabela 1 , estes listados na Tabela 3, gerados no presente estudo, estão mais próximos da realidade da bacia, tendo em vista que, através de trabalhos de campo e emprego de geotecnologias, observou-se que o processo de delimitação automática de bacias utilizando o modelo digital disponível (Morais et al. 2017) excluía uma sub-bacia com aproximadamente 37 $\mathrm{km}^{2}$, situada à montante da estação fluviométrica Fazenda Pão de Açúcar. Desta forma, foi necessário realizar uma correção neste modelo para contemplar tal área, passando a bacia de contribuição da estação Pão de Açúcar de 99 km² para $136 \mathrm{~km}^{2}$.

Tabela 3. Variáveis físicas e climáticas a serem utilizadas para transferência de vazão de referência na bacia do Rio Japaratuba.

\begin{tabular}{lcccc}
\hline $\begin{array}{c}\text { Estaçã } \\
\text { o }\end{array}$ & $\begin{array}{c}\text { Área de } \\
\text { contrib } \\
\text { uição } \\
\left(\mathrm{km}^{2}\right)\end{array}$ & $\begin{array}{c}\text { Compri } \\
\text { mento } \\
\text { da sub- } \\
\text { bacia } \\
(\mathrm{km})\end{array}$ & $\begin{array}{c}\text { Inclin } \\
\text { ação } \\
\text { média } \\
(\%)\end{array}$ & $\begin{array}{c}\text { Precipit } \\
\text { ação } \\
\text { média } \\
\text { anual } \\
(\mathrm{mm})\end{array}$ \\
\hline $\begin{array}{l}\text { Faz. } \\
\text { Pão }\end{array}$ & 136.62 & 22.35 & 0.83 & 988.97 \\
de & & & & \\
$\begin{array}{l}\text { Açúc } \\
\text { ar }\end{array}$ & & & & \\
$\begin{array}{l}\text { Faz. } \\
\text { Caju } \\
\text { eiro }\end{array}$ & 272.68 & 40.02 & 0.62 & $1,084.9$ \\
Siriri & 129.00 & 23.43 & 0.85 & $1,103.1$ \\
Rosá & 310.78 & 39.29 & 0.65 & $1,221.3$ \\
rio & & & & 6 \\
do & & & & \\
Catet & & & & \\
e & & & & \\
\hline
\end{tabular}

Pelos resultados obtidos, observa-se que a bacia contribuinte à estação Siriri apresenta a maior declividade média $(0,85 \%)$ e à Fazenda Cajueiro, a menor $(0,62 \%)$; a menor altura pluviométrica média anual ocorre sobre a bacia 
contribuinte ao posto Fazenda Pão de Açúcar, e a maior ocorre sobre a bacia contribuinte ao posto Rosário do Catete, sendo que esta amplitude se aproxima de $23 \%$ de diferença. Percebe-se que as diferenças quantitativas entre as variáveis físicas, considerando isoladamente os postos de montante e os de jusante, são inferiores a 5\%, excetuandose a área de contribuição, que atinge $14 \%$ entre os postos Rosário do Catete e Fazenda Cajueiro.

Nas Tabelas 4 a 7 são apresentados os valores de ERR (erro médio percentual) obtidos na transferência de vazão de referência de montante para jusante e vice-versa para as sub-bacias avaliadas. Conforme os dados na Tabela 4, os erros percentuais de transferência de vazões de montante para jusante na sub-bacia do rio Japaratuba-Mirim apresentaram grande variação. Assim observou-se que para as vazões mínimas e média os maiores erros foram obtidos utilizando a variável física Declividade média (em média 91,93 e $66,41 \%$ ) e os menores erros foram obtidos quando o produto Área x Precipitação média anual foi considerado, chegando a apenas $1,55 \%$ de erro. Tal melhoria pela inserção da precipitação também foi observada nos estudos de Pruski et al. (2015) e Cassalho et al. (2017).

Observou-se ainda que todos estes erros subestimaram os valores reais das vazões de referência, indicando estimativas inferiores ao valor real do posto Fazenda Cajueiro. Já em relação às vazões máximas, os maiores erros apresentados foram gerados pelo produto das variáveis Área x Precipitação média anual (em média $44,89 \%$ ) e os menores erros quando a variável Comprimento do rio (em média 18,48\%) foi considerada, indicando uma possível correlação direta entre o tempo de deslocamento da água nesta bacia e os valores de vazões máximas. Em estudo desenvolvido por Cassalho et al. (2017) e Lopes et al. (2017) e Morais et al. (2020), a área de drenagem e o comprimento do rio se caracterizaram como as variáveis mais expressivas para a representação nas funções regionalizadas. Para vazões máximas, os valores foram sempre superestimados, ou seja, as estimativas superaram os valores reais obtidos no posto Fazenda Cajueiro.

Para a transferência de vazões de referência no sentido de jusante para montante (Fazenda Cajueiro para Fazenda Pão de Açúcar) na bacia do rio Japaratuba-Mirim, observou-se um aumento significativo na ordem de grandeza dos erros cometidos (Tabela 5) comparativamente à transferência no sentido inverso (Tabela 4). Verificou-se ainda que para todas as vazões (mínimas, média e máximas) os maiores erros foram obtidos utilizando a variável física Declividade média, com superestimação em quase todas as variáveis, com exceção às vazões máximas para Área, Comprimento do rio e Área $\mathrm{x}$ Precipitação média anual.

Por outro lado, os menores erros para a determinação das vazões mínimas e média foram obtidos utilizando o produto Área x Precipitação média anual $(+1,58 \%)$, da mesma forma como ocorreu para a transferência de vazão de referência no sentido de montante para jusante. Os menores erros para vazões máximas foram obtidos utilizando a variável física Comprimento do rio (15,57\% em média), repetindo comportamento observado na transferência de vazões de referência de montante para jusante.

Observa-se que a ordem de grandeza dos erros cometidos segue o sentido inverso das dimensões das vazões, ou seja, quando os dados são transferidos da bacia maior para a bacia menor (Fazenda Cajueiro para Fazenda Pão de Açúcar) os erros na transferência de vazões pequenas (mínimas) são muito grandes (chegando a mais de 10 vezes), diminuindo à medida que a dimensão das vazões aumenta (média e máximas).

Assim como o que se observou para a subbacia do rio Japaratuba-Mirim, o comportamento dos erros médios percentuais cometidos pelas diferentes variáveis na transferência de montante para jusante na sub-bacia do rio Siriri (Tabela 6) apresentou predominância da subestimação dos valores reais. No entanto, os valores superestimados foram encontrados para as vazões mínimas e não para as máximas como na subbacia do Japaratuba-Mirim. Isto pode estar relacionado à maior condição de geração de vazão de base em montante na bacia do rio Siriri do que na do Japaratuba-Mirim, tendo em vista que há uma redução nas vazões específicas mínimas de montante para jusante na sub-bacia do rio Siriri. Assim observou-se que para as vazões mínimas os maiores erros foram cometidos com o produto Área x Precipitação média anual (em média 106,33\%) com subestimação; já os menores erros deveram-se a variável climática Precipitação média anual (14,35\% em média).

Em relação às vazões média e máximas, os maiores erros foram obtidos através da variável física Declividade média $(79,89 \%$ e $78,86 \%$ em média, respectivamente) e os menores erros com o 
produto Área x Precipitação média anual (29,88\% e $26,98 \%$ em média, respectivamente), todos com subestimação, conforme mostra a Tabela 6. Estes resultados diferem dos obtidos por Nruthya e Srinivas (2015) que afirmam que a declividade média, por controlar a velocidade do escoamento superficial, que também afeta o tempo que a água da chuva leva para concentrar-se na seção de drenagem da bacia, também afeta os valores de enchentes máximas. Esta diferença pode estar diretamente relacionada ao relevo da sub-bacia contribuinte ao posto Siriri, onde a declividade média, em virtude da presença do platô em boa parte da área, não representaria de forma adequada a relação com o tempo de resposta desta região. Este fato também foi ressaltado por Bazzo et al. (2017) e Arias et al. (2017).

Os processos de transferência de vazões de referências nas sub-bacias dos rios Siriri e Japaratuba-Mirim apresentaram comportamentos distintos quanto à variação dos erros médios percentuais, indicando diferentes variáveis de melhor performance para cada transferência de informação.

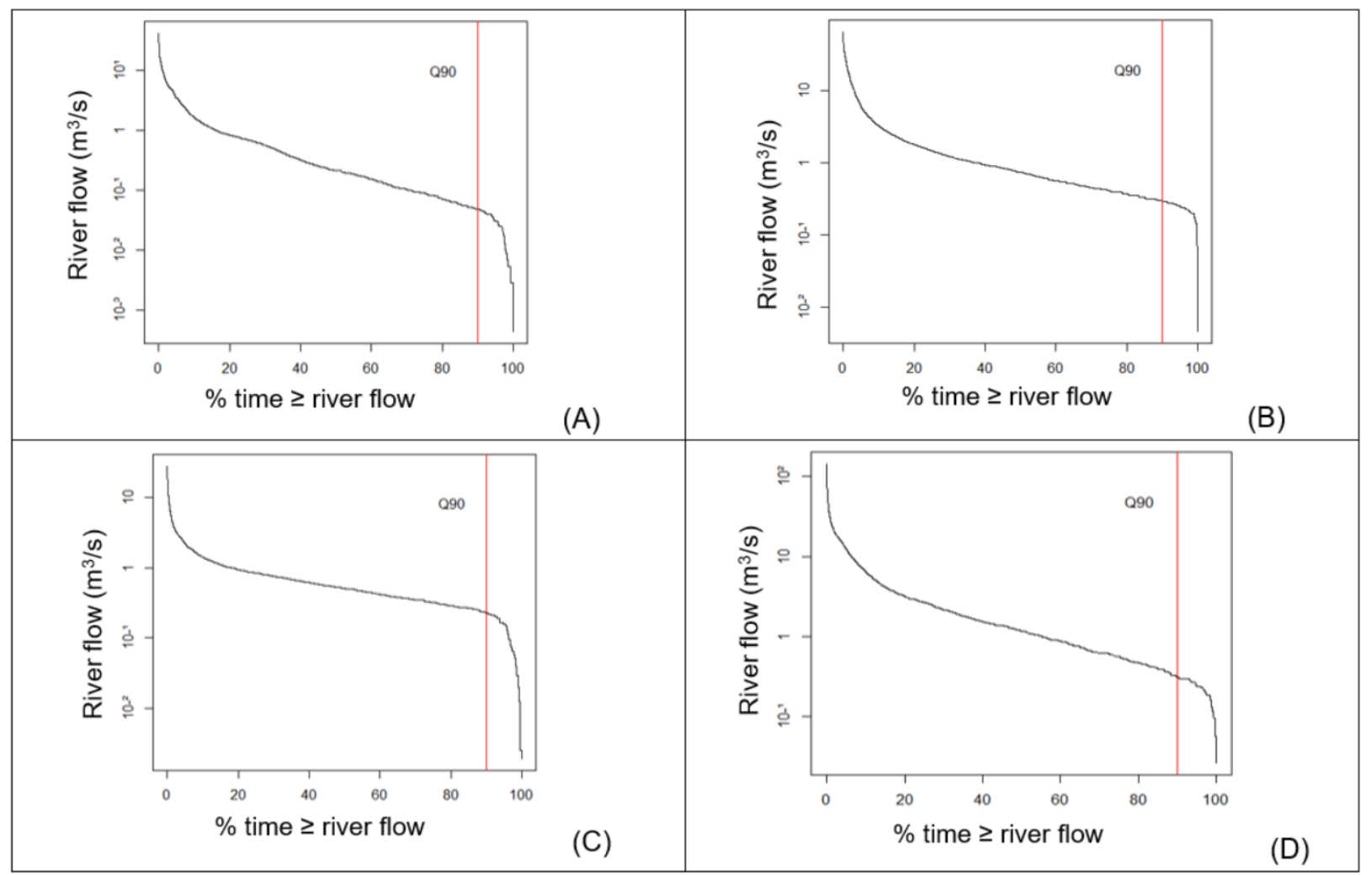

Figura 2. Curvas de duração das vazões mínimas utilizadas para definir $\mathrm{Q}_{90}$ nas estações Fazenda Pão de Açúcar (A), Fazenda Cajueiro (B), Siriri (C) e Rosário do Catete (D), da bacia hidrográfica do rio Japaratuba. 


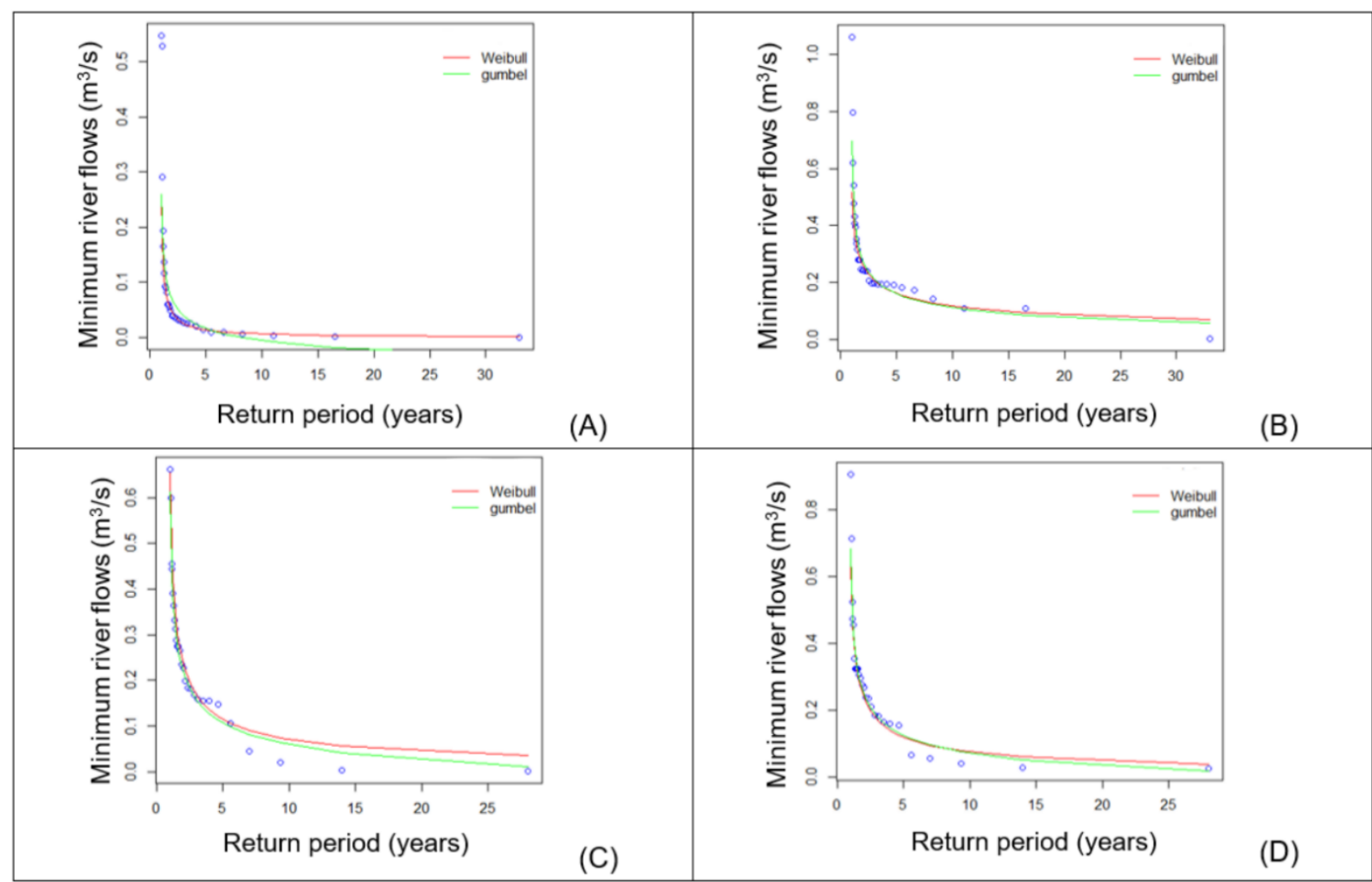

Figura 3. Ajustes na função de probabilidade de vazões mínimas utilizadas para definir $\mathrm{Q}_{7,10}$ nas estações Fazenda Pão de Açúcar (A), Fazenda Cajueiro (B), Siriri (C) e Rosário do Catete (D) na bacia do rio Japaratuba.

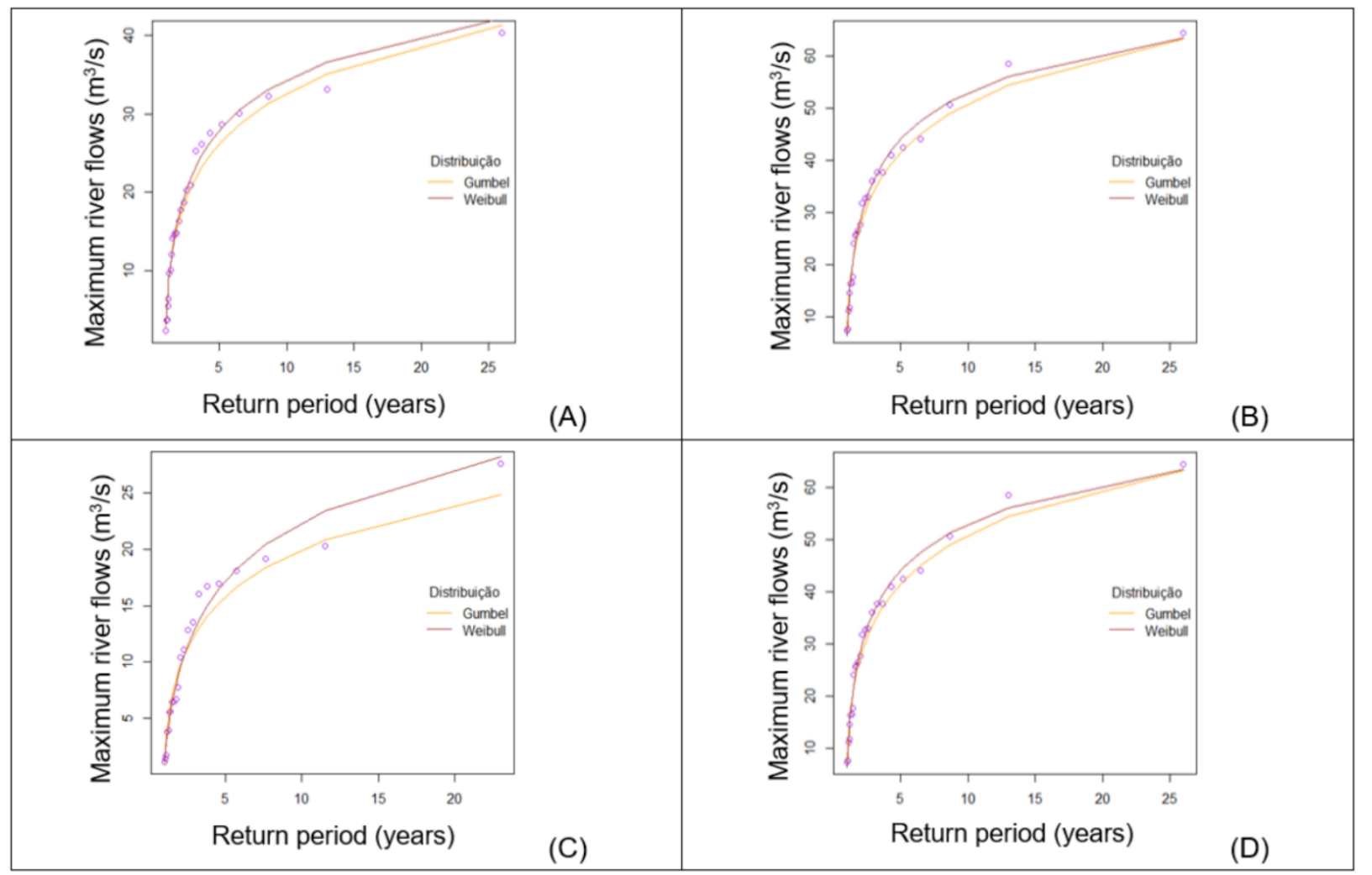

Figura 4. Ajustes na distribuição de probabilidade das vazões máximas utilizadas para definir $\mathrm{Q}_{\mathrm{TR}=10 \mathrm{anos}} \mathrm{e}$ $\mathrm{Q}_{\mathrm{TR}=50 \text { anos }}$ na estação Fazenda Pão de Açúcar (A), Fazenda Cajueiro (B), Siriri (C) e Rosário do Catete (D) na bacia do rio Japaratuba.

Cruz., M., A.,S., Junior., J., C., A., C., Gonçalves., A., A., Amorim., J., R., A., Aragão., R. 
Tabela 4. Valores de erros médios percentuais (ERR), obtidos na estimativa de vazões de referência nas estações Fazenda Cajueiro a partir da transferência de vazões da estação Fazenda Pão de Açúcar (montante para jusante - rio Japaratuba-Mirim).

\begin{tabular}{lccccc}
$\begin{array}{c}\text { Vazão de } \\
\text { referência }\end{array}$ & Área $\left(\mathrm{km}^{2}\right)$ & $\begin{array}{c}\text { Comprimento } \\
\text { do rio }(\mathrm{km})\end{array}$ & $\begin{array}{c}\text { Declividade } \\
\text { media }(\%)\end{array}$ & $\begin{array}{c}\text { Prec. Media } \\
\text { annual }(\mathrm{mm})\end{array}$ & $\begin{array}{c}\text { Área } \mathrm{x} \\
\text { precipitação } \\
\text { média anual }\end{array}$ \\
\hline $\mathrm{Q}_{90}$ & $-67.79 \%$ & $-71.11 \%$ & $-87.95 \%$ & $-82.30 \%$ & $-64.67 \%$ \\
$\mathrm{Q}_{7,10}$ & $-89.07 \%$ & $-90.19 \%$ & $-95.91 \%$ & $-93.99 \%$ & $-88.01 \%$ \\
$\mathrm{Q}_{\text {med }}$ & $-10.26 \%$ & $-19.50 \%$ & $-66.41 \%$ & $-50.67 \%$ & $-1.55 \%$ \\
$\mathrm{Q}_{\text {TR10anos }}$ & $+29.65 \%$ & $+16.31 \%$ & $-51.47 \%$ & $-28.73 \%$ & $+42.24 \%$ \\
$\mathrm{Q}_{\text {TR50anos }}$ & $+34.48 \%$ & $+20.64 \%$ & $-49.67 \%$ & $-26.08 \%$ & $+47.54 \%$ \\
\hline
\end{tabular}

Tabela 5. Valores de erro percentual médio (ERR) resultantes dos fluxos de referência estimados na estação Fazenda Pão de Açúcar com base na transferência de fluxo na estação Fazenda Cajueiro (Rio abaixo para montante - Rio Japaratuba-Mirim).

\begin{tabular}{lccccc}
\hline $\begin{array}{c}\text { Vazão de } \\
\text { referência }\end{array}$ & Área $\left(\mathrm{km}^{2}\right)$ & $\begin{array}{c}\text { Comprimento } \\
\text { do rio }(\mathrm{km})\end{array}$ & $\begin{array}{c}\text { Declividade } \\
\text { media }(\%)\end{array}$ & $\begin{array}{c}\text { Prec. Media } \\
\text { annual }(\mathrm{mm})\end{array}$ & $\begin{array}{c}\text { Área x } \\
\text { precipitação } \\
\text { média anual }\end{array}$ \\
\hline $\mathrm{Q}_{90}$ & $+210.50 \%$ & $+246.11 \%$ & $+729.61 \%$ & $+464.87 \%$ & $+183.03 \%$ \\
$\mathrm{Q}_{7,10}$ & $+814.95 \%$ & $+919.88 \%$ & $+2,344.60 \%$ & $+1,564.50 \%$ & $+733.99 \%$ \\
$\mathrm{Q}_{\text {med }}$ & $+11.44 \%$ & $+24.22 \%$ & $+197.75 \%$ & $+102.73 \%$ & $+1.58 \%$ \\
$\mathrm{Q}_{\text {TR10anos }}$ & $-22.87 \%$ & $-14.03 \%$ & $+106.08 \%$ & $+40.31 \%$ & $-29.70 \%$ \\
$\mathrm{Q}_{\text {TR50anos }}$ & $-25.64 \%$ & $-17.11 \%$ & $+98.68 \%$ & $+35.28 \%$ & $-32.22 \%$ \\
\hline
\end{tabular}

Tabela 6. Valores de erros médios percentuais (ERR) obtidos na estimativa de vazões de referência na estação Rosário do Catete a partir da transferência de vazões da estação Siriri (montante para jusante - rio Siriri).

\begin{tabular}{lccccc}
\hline $\begin{array}{c}\text { Vazão de } \\
\text { referência }\end{array}$ & Área $\left(\mathrm{km}^{2}\right)$ & $\begin{array}{c}\text { Comprimento } \\
\text { do rio }(\mathrm{km})\end{array}$ & $\begin{array}{c}\text { Declividade } \\
\text { media }(\%)\end{array}$ & $\begin{array}{c}\text { Prec. Media } \\
\text { annual }(\mathrm{mm})\end{array}$ & $\begin{array}{c}\text { Área x } \\
\text { precipitação } \\
\text { média anual }\end{array}$ \\
\hline $\mathrm{Q}_{90}$ & $+82.22 \%$ & $+26.86 \%$ & $-42.16 \%$ & $-16.25 \%$ & $-101.75 \%$ \\
$\mathrm{Q}_{7,10}$ & $+90.49 \%$ & $+32.61 \%$ & $-39.53 \%$ & $-12.45 \%$ & $-110.90 \%$ \\
$\mathrm{Q}_{\text {med }}$ & $-36.67 \%$ & $-55.91 \%$ & $-79.90 \%$ & $-70.89 \%$ & $-29.88 \%$ \\
$\mathrm{Q}_{\text {TR 10anos }}$ & $-33.66 \%$ & $-53.82 \%$ & $-78.94 \%$ & $-69.51 \%$ & $-26.55 \%$ \\
$\mathrm{Q}_{\text {TR50anos }}$ & $-33.16 \%$ & $-53.47 \%$ & $-78.78 \%$ & $-69.28 \%$ & $-26.00 \%$ \\
\hline
\end{tabular}

Tabela 7. Valores de erro percentual médio (ERR) das estimativas de vazão de referência na estação Siriri com base nas transferências de vazão da estação Rosário do Catete (jusante a montante - Rio Siriri).

\begin{tabular}{cccccc}
$\begin{array}{c}\text { Vazão de } \\
\text { referência }\end{array}$ & Área $\left(\mathrm{km}^{2}\right)$ & $\begin{array}{c}\text { Comprimento } \\
\text { do rio }(\mathrm{km})\end{array}$ & $\begin{array}{c}\text { Declividade } \\
\text { media }(\%)\end{array}$ & $\begin{array}{c}\text { Prec. Media } \\
\text { annual }(\mathrm{mm})\end{array}$ & $\begin{array}{c}\text { Área } \mathrm{x} \\
\text { precipitação } \\
\text { média anual }\end{array}$ \\
\hline
\end{tabular}




\begin{tabular}{llllll}
\hline $\mathrm{Q}_{90}$ & $-45.12 \%$ & $-21.17 \%$ & $+72.88 \%$ & $+19.40 \%$ & $+50.43 \%$ \\
$\mathrm{Q}_{7,10}$ & $-47.50 \%$ & $-24.59 \%$ & $+65.38 \%$ & $+14.22 \%$ & $+52.58 \%$ \\
$\mathrm{Q}_{\text {med }}$ & $+57.90 \%$ & $+126.81 \%$ & $+397.43 \%$ & $+243.56 \%$ & $+42.62 \%$ \\
$\mathrm{Q}_{\text {TR10anos }}$ & $+50.74 \%$ & $+116.52 \%$ & $+374.86 \%$ & $+227.98 \%$ & $+36.15 \%$ \\
$\mathrm{Q}_{\text {TR50anos }}$ & $+49.62 \%$ & $+114.92 \%$ & $+371.34 \%$ & $+225.55 \%$ & $+35.14 \%$ \\
\hline
\end{tabular}

Isto pode estar relacionado às diferentes características presentes nas bacias estudadas, como a predominância de áreas vegetadas naturais na bacia do Japaratuba-Mirim, principalmente em sua porção de montante, diferentemente da subbacia do rio Siriri com maior predominância de pastagens e áreas agrícolas (cana-de-açúcar), bem como solos com maior condição de manutenção de umidade e maiores alturas pluviométricas.

Pode-se observar que em ambas as subbacias estudadas, a seleção das variáveis de menor ERR independe do sentido de avaliação, ou seja, as variáveis que apresentaram o menor erro em um sentido (montante-jusante) o apresentam também no sentido oposto para todas as vazões de referência. Tal fato não se observou na sub-bacia do rio Siriri, quanto à variável de pior resultado, tendo em vista que o sentido de avaliação gerou alterações nas variáveis para as vazões mínimas. Este comportamento pode ser um reflexo da antropização, mais presente na área desta sub-bacia associada também às mudanças na variação altimétrica, já citada anteriormente.

Nas duas sub-bacias ocorreu uma predominância de subestimação nos valores de vazões de referência estimados quando o processo se dava de montante para jusante (da menor para a maior bacia contribuinte), ocorrendo o inverso, ou seja, superestimando os valores quando o processo ocorria de jusante para montante, ou seja, da maior área contribuinte para a menor. No entanto esta superestimação não foi observada em todas as variáveis: na sub-bacia Japaratuba-Mirim, para vazões máximas transpostas pela Área, Comprimento e Área x Precipitação Média Anual e, na sub-bacia Siriri, para mínimas, transpostas pela Área e Comprimento do rio, ocorreu subestimação.

A partir dos resultados obtidos, pode-se recomendar que transferências em ambos os sentidos (montante para jusante e jusante para montante) na sub-bacia do rio Japaratuba-Mirim devem utilizar o produto Área x Precipitação média anual para estimar vazões mínimas e média, e o
Comprimento do rio para as vazões máximas. Ressalte-se que as superestimativas nas vazões mínimas, no sentido jusante-montante foram excessivas, não aconselhando o seu emprego. Já para a sub-bacia do rio Siriri, para a transferência de vazões de referência no sentido de montante para jusante, recomenda-se a aplicação da Precipitação média anual da bacia contribuinte para vazões mínimas e Área x Precipitação média anual para a média e vazões máximas.

Os resultados foram obtidos considerandose apenas a razão direta entre as vazões a serem estimadas e as variáveis de transferência, sem a avaliação de pesos, coeficientes ou expoentes. Entende-se que tal avaliação demandaria a existência de um número maior de postos com séries históricas de durações superiores a 10 anos, o que não se dispõe nesta bacia até o presente momento. No entanto, os resultados gerados podem servir de subsídio aos órgãos púbicos responsáveis pelos processos de gestão dos recursos hídricos no estado de Sergipe visando avaliar as metodologias hoje em uso e aumentar a conscientização dos técnicos e do público interessado quanto ao grau de erro que pode estar sendo cometido na consideração simples da área de contribuição (vazão específica) para estimar vazões em locais sem dados, por exemplo.

\section{Conclusão}

1) O estudo realizado permitiu a avaliação da grandeza dos erros médios relativos cometidos na transferência de vazões de referência mínimas, média e máximas por meio de variáveis físicas e climática na bacia do rio Japaratuba, considerando dois de seus afluentes principais, os rios Siriri e Japaratuba-Mirim.

2) Os resultados apontam para comportamentos diferentes nas duas sub-bacias, com relação às melhores variáveis escolhidas em cada transferência, apontando para efeitos externos que devem ser melhor estudados, 
como influência do tipo de solo e da mudança de uso da terra.

3) Em ambas as sub-bacias houve uma tendência de subestimação nos valores de vazões de referência quando o processo se dava de montante para jusante (da menor para a maior bacia contribuinte), ocorrendo o inverso, ou seja, superestimando os valores quando o processo ocorria de jusante para montante, ou seja, da maior área contribuinte para a menor.

4) Na sub-bacia do rio Japaratuba Mirim, os resultados apontam para que as transferências de vazões de referência, em ambos os sentidos, ou seja, montante para jusante e vice-versa, sejam realizadas por meio do uso do produto área e precipitação média anual para vazões mínimas e média, e do comprimento do rio para vazões máximas.

5) Para a sub-bacia do rio Siriri, para a transferência de vazões de referência no sentido de montante para jusante, recomenda-se a aplicação da precipitação média anual da bacia contribuinte para vazões mínimas e do produto entre área e precipitação média anual para vazões média e máximas.

6) Diante dos resultados apresentados, verifica-se a necessidade de avaliar outras combinações de variáveis e realizar esses estudos em outras bacias hidrográficas do estado de Sergipe visando validar estas verificações.

7) Faz-se necessário também um maior investimento em instrumentação para obtenção dos registros de vazões no sentido de minimizar as falhas que foram encontradas nas séries históricas dos quatro postos fluviométricos da bacia hidrográfica do Japaratuba e permitir a avaliação de outras dimensões de bacias contribuintes.

\section{Agradecimentos}

A Embrapa Tabuleiros Costeiros, a Secretaria de Recursos Hídricos do Estado de Sergipe, a Universidade Federal de Sergipe através do Programa de Pós-graduação em Recursos Hídricos, a Universidade Federal de Campina Grande e a Agência Nacional de Águas.

\section{Referências}

Acieri, M.S., Cruz, M.A.S., Lucas, T.A.A., Aragão, R., 2019. A dinâmica hidrológica das vazões do rio Japaratuba mirim, afluente da bacia hidrográfica do rio Japaratuba - Sergipe. In: anais do XXIII Simpósio Brasileiro de Recursos Hidrícos, Foz do Iguaçu, 2019.
Disponível:

https://s3-sa-east-

1.amazonaws.com/abrh/Eventos/Trabalhos/107 /XXIII-SBRH0587-1-20190504-155709.pdf.

Acesso: 25 mai. 2020.

Al-Jawad, J. Y.; Alsaffar, H. M.; Bertram, D.; Kalin, R. M., 2019. A comprehensive optimum integrated water resources management approach for multidisciplinary water resources management problems. Journal of Environmental Management [online] 239. Disponível: https://doi.org/10.1016/j.jenvman.2019.03.045. Acesso: 21 jun. 2019.

ANA. Agência Nacional de Águas. 2020. Portal Hidroweb. Brasília, DF. Disponível: http://hidroweb.ana.gov.br/. Acesso: 19 jan. 2020.

ANA. Agência Nacional de Águas. 2017. Conjuntura dos Recursos hídricos no Brasil. Brasília, DF. Disponível: http://arquivos.ana.gov.br/institucional/spr/con juntura/ANA_Conjuntura_Recursos_Hidricos_ Brasil/ANA_Conjuntura_Recursos_Hidricos_ Brasil_2013_Final.pdf. Acesso: 27 out. 2017.

Aragão, R., Cruz, M.A.S., Amorim, J.R.A., Mendonça, L.C., Figueiredo, E.E., Srinivasan, V.S., 2013. Análise de sensibilidade dos parâmetros do modelo SWAT e simulação dos processos hidrossedimentológicos em uma bacia no Agreste nordestino. Revista Brasileira de Ciência do Solo [online] 37. Disponível: https://doi.org/10.1590/S010006832013000400026 . Acesso: 14 jul. 2019.

Arias, S.G., Serna, L.F.C., 2017. Regionalization of flow duration curves in the state of Antioquia, Colombia. Revista EIA [online] 14. Disponível:

https://doi.org/10.24050/reia.v14i27.1158. Acesso: 27 dez. 2019.

Bazzo, K.R., Guedes, H.A.S., Castro, A.S., Siqueira, T.M. Teixeira-Gandra, C.F.A., 2017. Regionalização da vazão $\mathrm{Q}_{95}$ : comparação de métodos para a bacia hidrográfica do Rio Taquari-Antas, RS Rev. Ambiente e Água [online] 12. Disponivel: http:// doi:10.4136/ambi-agua.2032. Acesso: 20 maio 2020.

Brasil, 1997. Lei no 9.433, de 8 de janeiro de 1997 - Institui a Política Nacional de Recursos Hídricos, cria o Sistema Nacional de Gerenciamento de Recursos Hídricos, regulamenta o inciso XIX do art. 21 da Constituição Federal, e altera o art. 1o da Lei no 8.001, de 1, 1997 [online]. 
Disponível:http://www.planalto.gov.br/ccivil_ 03/LEIS/L9433.htm. Acesso: 20 jun. 2020.

Calegario, A.T., Pruski, F.F., Ribeiro, R.B., Ramos, M.C.A., Rego, F.S., 2020. Physical Analysis of Regionalized Flow as an aid in the Identification of Hydrologically Homogeneous Regions. Engenharia Agrícola [online] 40. Disponível: http://dx.doi.org/10.1590/18094430-Eng.Agric.v40n3p334-343/2020. Acesso: 6 ago. 2020.

Cassalho, F., Beskow, S., Vargas, M.M., Moura M.M., Ávila, L.F., Mello, C.R., 2017. Hydrological regionalization of maximum stream flows using an approach based on Lmoments. Revista Brasileira de Recursos Hídricos [online] 22. Disponível: http:// http://dx.doi.org/10.1590/23180331.021720160064. Acesso: 20 maio 2020.

Cruz, M.A.S., Gonçalves, A.D., Aragão, R., Amorim, J.R.A., Mota, P.V.M., Srinivasan, V.S., Garcia, C.A.B., Figueiredo, E.E., 2019. Spatial and seasonal variability of the water quality characteristics of a river in Northeast Brazil. Environmental Earth Sciences [online] 78. Disponível: https://doi.org/10.1007/s12665019-8087-5. Acesso: 01 dez. 2019.

Gomes, R. R. K. de A.; Fernandes, L. L., 2017. Hydrological characterization of the Araguaia River through reference flows. Appl Water Sci. [online] 7.7 Disponível: https://doi.org/10.1007/s13201-017-0622-5. Acesso: 10 dez. 2019.

Javeed, Y., Apoorva, K.V., 2015. Flow Regionalization under Limited Data Availability - Application of IHACRES in the Western Ghats. Aquatic procedia [online] 4. Disponível:

https://doi.org/10.1016/j.aqpro.2015.02.117. Acesso: 12 abr. 2020.

Lopes, T.R., Zolin, C.A., Prado, G., Paulino, J., Almeida, F.T., 2017. Regionalization of maximum and minimum flow in the Teles Pires basin, Brazil. Engenharia Agrícola [online] 37. Disponível: https://doi.org/10.1590/1809-4430eng.agric.v37n1p54-63/2017. Acesso: 14 mai. 2020.

Lelis, L.C.S., Nascimento, J.G., Duarte, S.N., Pacheco, A.B., Bosquilia, R.W.D., Wolff, W., 2019. Assessment of hydrological regionalization methodologies for the upper Jaguari River basin. Journal of South American Earth Sciences, Disponível: https://doi.org/10.1016/j.jsames.2019.102402. Acesso: 14 jul. 2020.
Maciel, A.L., Vieira, E.M., Monte Mor, R.C., Vasques, A.C., 2019. Regionalização e Espacialização de Vazões de Permanência: Estudo Aplicado na Bacia rio Piracicaba-mg. Revista Brasileira de Climatologia [online] 24. Disponível: http://dx.doi.org/10.5380/abclima.v24i0.58420. Acesso: 20 maio 2020.

Maynard, I.F.N., Gomes, L.J., Cruz, M.A.S., 2017. Applying a sustainability index to the Japaratuba river wathershed in Sergipe state. Ambiente e Sociedade [online] 20. Disponível: http://doi:10.1590/1809-

4422ASOC0057R1V2022017. Acesso: $20 \mathrm{dec}$. 2019.

Melati, M.D., Marcuzzo, F.F.N., 2016. Regressões simples e robusta na regionalização da vazão Q95 na Bacia Hidrográfica do Taquari-Antas. Ciência e Natura [online] 38. Disponível: http://doi:10.5902/2179-460X19116, 2, 722-739. Acesso: 25 ago. 2019.

Młyński, D.; Wałęga, A.; Ozga-Zielinski, B.; Ciupak, M.; Petroselli, A., 2020. New approach for determining the quantiles of maximum annual flows in ungauged catchments using the EBA4SUB model. Journal of Hydrology [online] 289.2 Disponível: https://doi.org/10.1016/j.jhydrol.2020.125198. Acesso: 10 set. 2020.

Morais, J.D., Faria, T.S., Elmiro, M.A.T., Nero, M.A., Silva, A.A., Nobrega, R.A.A., 2017. Altimetry Assessment of Aster GDEM V2 and SRTM V3 Digital Elevation Models: A Case Study in Urban Area of Belo Horizonte, MG, Brazil. Bull. Geod. Sci. [online] 23. Disponível: http://dx.doi.org/10.1590/S1982-

21702017000400043. Acesso: 8 marc. 2019.

Morais, M.A.V., Viola, M.R., Mello, C.R., Rodrigues, J.A.M., Oliveira, V.A., 2020. Regionalization of reference stream flows for the Araguaia River basin in Brazil. Semina: Ciências Agrárias [online] 41. Disponível: http://dx.doi.org/10.5433/16790359.2020v41n3p829. Acesso: 20 de out. 2020.

Nruthya. K.; Srinivas, V., 2015. Evaluating Methods to Predict Streamflow at Ungauged Sites using Regional Flow Duration Curves: A Case Study. Aquatic Procedia [online] 4. Disponível:https://doi.org/10.1016/j.aqpro.201 5.02.083. Acesso: 30 jun. 2019.

ONU - Organização das Nações Unidas, 2020. UN World Water Development Report 2020:Water and Climate Change. UN [online] 
Disponível:https://www.unwater.org/publicatio ns/world-water-development-report-2020/.

Acesso: 20 abr. 2020.

ONU, 2015. Water for a Sustainable World. The United Nations world water development Report 2015, v. 1. Disponível: http://www.agenda2030.com.br/. Acesso: 13 out. 2020.

Prieto, C., Vine, N.L., Kavetski, D., García, E., Medina, R.,2019. Flow prediction in ungauged catchments using probabilistic Random Forests regionalization and new statistical adequacy tests. Water Resources Research [online] 55. Disponível:https://doi.org/10.1029/2018WR02 3254. Acesso: 5 out. 2020.

Pruski, F.F., Rodriguez, R.D.G., Nunes, A.A., 2015. Low-flow estimates in regions of extrapolation of the regionalization equations: a new concept. Engenharia Agrícola [online] 35. Disponível: https://doi.org/10.1590/1809-4430Eng.Agric.v35n5p808-816/2015. Acesso: 20 marc. 2020.

$\mathrm{R}$ Core Team (2018). R: A language and environment for statistical computing. $\mathrm{R}$ Foundation for Statistical Computing, Vienna, Austria. Disponível: https://www.Rproject.org/. Acesso: 10 nov. 2019.

Santos, A.R., Guimarães, T.T., Mauad, F.F, Okawa, C.M.P., 2019. Regionalization of average flow: a brief review of the literature. Revista Eletrônica em Gestão Educação e Tecnologia Ambiental [online] 23. Disponível: http:// doi:10.5902/2236117039844. Acesso: 20 maio 2020.

Schneider, E.H.M., Barbosa, A.G., Rocha, I.M.L., Mendes, L.A., 2019. Regionalização das vazões de permanência para as bacias hidrográficas do Estado de Sergipe segundo suas regiões climáticas. Scientia Plena [online] 13. Disponível: http://doi: 10.14808/sci.plena.2017.109901. Acesso: 20 maio 2020.

SERGIPE. Secretaria de Estado do Meio Ambiente e dos Recursos Hídricos. 2015. Elaboração dos planos das bacias hidrográficas dos rios Japaratuba, Piauí e Sergipe. Relatório de Resumo Executivo - Bacia do rio Japaratuba. Aracaju, SE: Secretaria de Estado do Meio Ambiente e dos Recursos Hídricos, oct. 2015. Disponível:

https://www.semarh.se.gov.br/recursoshidricos /wp-content/uploads/2018/05/RESUMOEXECUTIVO-BH-JAPARATUBA.pdf.
Silva, B.M.B., Silva, D.D., Moreira, M.C., 2015. Influência da sazonalidade das vazões nos critérios de outorga de uso da água: estudo de caso da bacia do rio Paraopeba. Revista Ambiente e Água [online] 10. Disponível: https://doi.org/10.4136/ambi-agua.1587. Acesso: 20 dez. 2019.

Silva, C.O.F., Manzione, R.L., 2020. Revisitando a Regionalização de Vazões na Região do Médio Paranapanema no Estado de São Paulo: Utilização de Curvas de Permanência em Microbacias Hidrográficas. Revista do Instituto Geológico [online] 41. Disponível: http://doi.org/10.33958/revig.v41i2.678.

Acesso: 10 set. 2020.

Silva, C.L., Bassi, S.S., Rocha Junior, W.F., 2016. Technologies for rational water use in Brazilian agriculture. Revista Ambiente e Água [online] 11. Disponível: https://doi.org/10.4136/ambiagua.1808. Acesso: 10 jun. 2020.

Swaina, J.B., Jhab, R., Patrac, K.C., 2015. Stream flow prediction in a typical ungauged catchment using GIUH approach. Aquatic Procedia [online] Disponível:https://doi.org/10.1016/j.aqpro.201 5.02.125. Acesso: 10 out. 2019.

Tormam, M.F., Guedes, H.A.S., Bork, C.K., Fraga, M.S., 2020. Low flows hydrological regionalization and definition of homogeneous regions using multivariate statistical analyses in the Uruguai River watershed, on the Rio Grande do Sul State side, Brazil. Revista Brasileira de Geografia Física [online] 13. Disponível: https://doi.org/10.26848/rbgf.v13.6.p30783094. Acesso: 10 mar. 2020.

Tucci, C.E.M., 2013. Hidrologia: ciência e aplicação, 4. ed. Editora da Universidade: ABRH, Porto Alegre.

Yang, X., Magnusson, J., Huang, S., Beldring, S., Xu, C-Y., 2020. Dependence of regionalization methods on the complexity of hydrological models in multiple climatic regions. Journal of Hydrology [online] 582. Disponível: https://doi.org/10.1016/j.jhydrol.2019.124357. Accesso: 08 ago. 2020.

Zhao, C.S., Yang, Y., Yang, S.T., Xiang, H., Ge, Y.R., Zhang, Z.S., Zhao, Y., Yu, Q., 2019. Effects of spatial variation in water quality and hydrological factors on environmental flows. Science of The Total Environment. [728] Disponível:https://doi.org/10.1016/j.scitotenv.2 020.138695. Acesso: 15 abr. 2020. Acesso: 20 nov. 2019. 